\title{
Preparation and studies of electrical properties of cobalt substituted Li-Zn ferrites by sol-gel auto combustion method
}

\author{
Ibetombi Soibam ${ }^{1}$, Sumitra Phanjoubam ${ }^{1}$, H B Sharma ${ }^{1}$, H N K Sarma ${ }^{1}$ \\ and Chandra Prakash ${ }^{2}$ \\ ${ }^{1}$ Department of Physics, Manipur University, Canchipur, Imphal-795 003, Manipur, India \\ ${ }^{2}$ Directorate of ER \& IPR, DRDO Bhawan, Rajaji Marg, New Delhi-110 011, India \\ E-mail : ibetombi_phys@rediffimail.com
}

Received 18 June 2008, accepted 29 September 2008

\begin{abstract}
A series of Co substituted lithium zinc ferrite powders with different content of Co (0.00 to 0.1 in steps of 0.02 ) were prepared by a novel sol-gel auto combustion process using citric acid. Their spinel structure was confirmed by XRD. The variation in lattice parameter and density with cobalt concentration was studied which showed an increasing trend. A decreasing pattern was observed in variation of porosity with increasing Co. Room temperature dielectric constant and resistivity were studied as a function of composition at $10 \mathrm{KHz}$. The room temperature dielectric constant decreases with successive addition of $\mathrm{Co}^{2+}$ in the series. The observed variation in dielectric constant has been explained on the basis of space charge polarization and Koops two layer model. Resistivity is observed to increase with increasing concentration and the observed variation in resistivity has been explained by Verwey hopping mechanism.

Keywords : Spinel phase, electrical, sol-gel, fine particles

PACS Nos. : 78.67.Bf, 72.15.Eb
\end{abstract}

\section{Introduction}

Ferrites represent an important category of materials, which are in great demand due to their numerous practical applications. Lithium and substituted lithium ferrite are among them and are gaining importance because of their technological applications ranging from microwave to radio frequency. The electrical and magnetic properties of ferrites are strongly dependent on their chemical composition and their method of preparation in general [1-3]. One of the most popular nonconventional synthesis method used in the solgel auto

\footnotetext{
* Corresponding Author
} 
combustion method which is a promising technique for obtaining highly homogenous ferrite powders with nanocrystallite size [4]. Several studies have also been reported with addition of divalent, trivalent and tetravalent ions to study various parameters depending on the intended application of the ferrites. With a view to understand the effect of Co substitution a series of Co substituted lithium zinc ferrites were synthesized and studies were made on electrical characterization of the synthesized material.

\section{Experiment}

Cobalt substituted lithium zinc ferrites with compositional formula $\mathrm{Li}_{0.4-0.5 \mathrm{x}} \mathrm{Zn}_{0.2} \mathrm{Co}_{\mathrm{x}}$ $\mathrm{Fe}_{2.4-0.5 x} \mathrm{O}_{4}$ where $\mathrm{x}=0.0 \leq \mathrm{x} \leq 0.1$ in steps of 0.02 were prepared by the sol-gel auto combustion method. The starting chemicals used were lithium nitrate, zinc nitrate, iron nitrate, cobalt nitrate and citric acid. Stoichiometric amount of lithium nitrate, zinc nitrate, cobalt nitrate and iron nitrate were put in a beaker to make a solution, to which citric acid was added. The final solution was then refluxed at $40^{\circ} \mathrm{C}$ after controlling the $\mathrm{pH}$ at 7 to get a homogenous mixture. After refluxing, auto combustion was made to occur at $100^{\circ} \mathrm{C}$. The ash-synthesize product so obtained is the typical spinel structured lithium ferrite powder with nanocrystallite size. The synthesized powder was mixed with polyvinyl alcohol as binder and pressed into pellets using 50 kilo Newton pressure. It was then sintered at $1050^{\circ} \mathrm{C}$ for 11 hours in air at a slow heating rate of $5^{\circ} \mathrm{C} / \mathrm{min}$. and then furnace cooled. XRD was used to identify the spinel phase. The lattice parameter and X-ray density was calculated from the XRD data and their variation with composition studied. Experimental density of the samples was calculated using Archimedes' Principle. The grain size was calculated from XRD data using Debye Scherrer formula. Porosity was calculated from experimental and theoretical density. The capacitance was measured using an Agilent HP

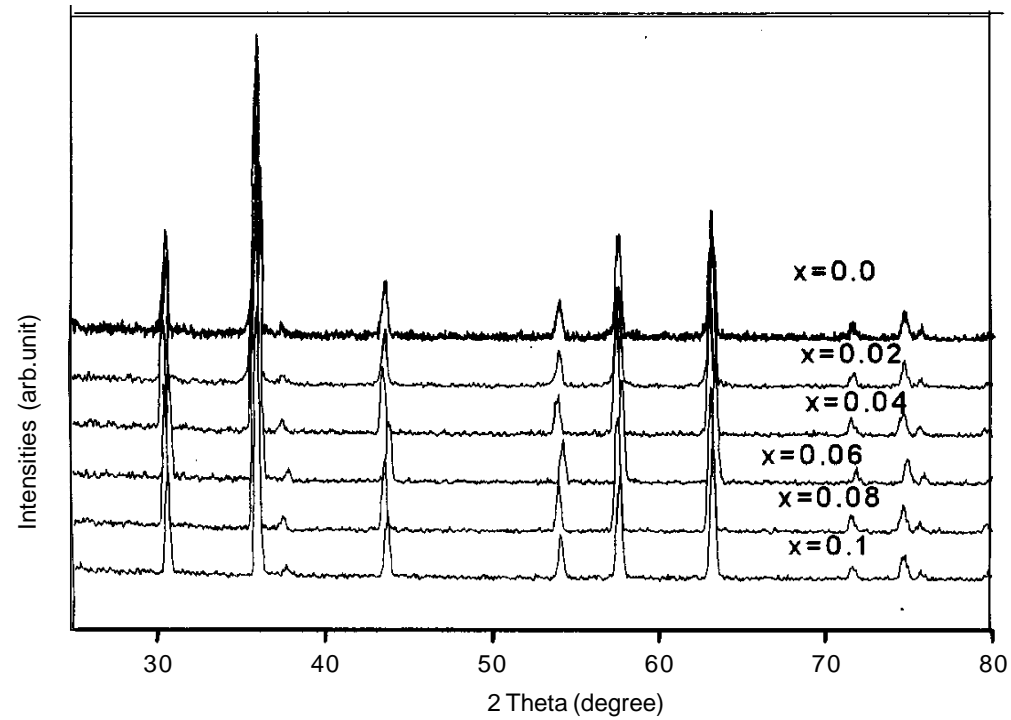

Figure 1. $\mathrm{XRD}$ for $\mathrm{Li}_{0.4-0.5 \mathrm{x}} \mathrm{Xn}_{0.2} \mathrm{Co}_{\mathrm{x}} \mathrm{Fe}_{2.4-15 \mathrm{x}} \mathrm{O}_{4}, \mathrm{x}=0.00-0.1$ in steps of 0.02 . 
4284A LCR meter and the value of dielectric constant was calculated using the formula $\varepsilon^{\prime}=C d / \varepsilon_{0} A$ where $C$ is the measured capacitance, $d$ the thickness, A the cross sectional area of the sample and $\varepsilon_{0}$ the permittivity of free space. The room temperature resistivity was measured using two probe method.

\section{Results and discussion}

XRD pattern shown in Figure 1 confirms the single phase spinel structure of lithium zinc cobalt ferrites. No characteristic peak of impurities is detected in the XRD patterns of all the samples.

The lattice parameter determined from the XRD data showed variation with composition, shown in Table 1. The lattice constant shows a linear increase with increasing cobalt content. These variations in lattice constant can be explained on the basis of lattice expansion. If the radius of doping ion is larger than the displaced ion the lattice expands and lattice constant increases. Reverse will hold if a smaller doping ion replaces a metal ion of the regular lattice. In $\mathrm{Li}_{0.4-0.5 x} \mathrm{Zn}_{0.2} \mathrm{Co}_{x} \mathrm{Fe}_{2.4-0.5 x} \mathrm{O}_{4}$ ferrites, $\mathrm{Co}^{2+}$ ions with radius $0.082 \mathrm{~nm}$ substitutes $\mathrm{Fe}^{3+}$ ions and $\mathrm{Li}^{1+}$ ions with radius $0.067 \mathrm{~nm}$ and $0.078 \mathrm{~nm}$ respectively. An increase in lattice parameter is therefore expected, as has been observed. The densities of the various samples as measured by the archimedes' Principle and those calculated from the XRD data are also tabulated in Table 1 . The densities increase with increasing $\mathrm{Co}^{2+}$ concentration and similar results were observed by different workers $[5,6]$. The measured densities of the samples are observed to be $81 \%$ to $83 \%$ of their theoretical values.

\begin{tabular}{|c|c|c|c|c|}
\hline Composition & $\begin{array}{c}\text { Lattice parameter } \\
(\AA)\end{array}$ & $\begin{array}{l}\text { Theoretical } \\
\text { density } \\
\left(\mathrm{gm} / \mathrm{cm}^{3}\right)\end{array}$ & $\begin{array}{c}\text { Experimental } \\
\text { density } \\
\left(\mathrm{gm} / \mathrm{cm}^{3}\right)\end{array}$ & $\begin{array}{l}\text { Grain size } \\
(\mathrm{nm})\end{array}$ \\
\hline $\mathrm{Li}_{0.4} \mathrm{Zn}_{0.2} \mathrm{Fe}_{2.4} \mathrm{O}_{4}$ & 8.307 & 4.9558 & 4.016 & 28 \\
\hline $\mathrm{Li}_{0.39} \mathrm{Zn}_{0.2} \mathrm{Co}_{0.02} \mathrm{Fe}_{2.39} \mathrm{O}_{4}$ & 8.310 & 4.9634 & 4.042 & 27 \\
\hline $\mathrm{Li}_{0.38} \mathrm{Zn}_{0.2} \mathrm{Co}_{0.04} \mathrm{e}_{2.38} \mathrm{O}_{4}$ & 8.315 & 4.9669 & 4.069 & 33 \\
\hline $\mathrm{Li}_{0.37} \mathrm{Zn}_{0.2} \mathrm{Co}_{0.06} \mathrm{e}_{2.37} \mathrm{O}_{4}$ & 8.302 & 5.0033 & 4.096 & 33 \\
\hline $\mathrm{Li}_{0.36} \mathrm{Zn}_{0.2} \mathrm{Co}_{0.08} \mathrm{Fe}_{2.36} \mathrm{O}_{4}$ & 8.316 & 5.0035 & 4.122 & 31 \\
\hline $\mathrm{Li}_{0.35} \mathrm{Zn}_{0.2} \mathrm{Co}_{0.1} \mathrm{Fe}_{2.35} \mathrm{O}_{4}$ & 8.320 & 5.0090 & 4.149 & 26 \\
\hline
\end{tabular}

The crystallite size has been calculated using Debye Scherrer formula and is found to be in range of $25 \mathrm{~nm}$ to $35 \mathrm{~nm}$. Figure 2 shows the variation of porosity with $\mathrm{Co}^{2+}$ concentration. It is observed that the porous nature decreases with increasing $\mathrm{Co}^{2+}$ content; in agreement with observations by previous workers [15]. 
The variation of room temperature dielectric constant and resistivity are shown in Figure 3.

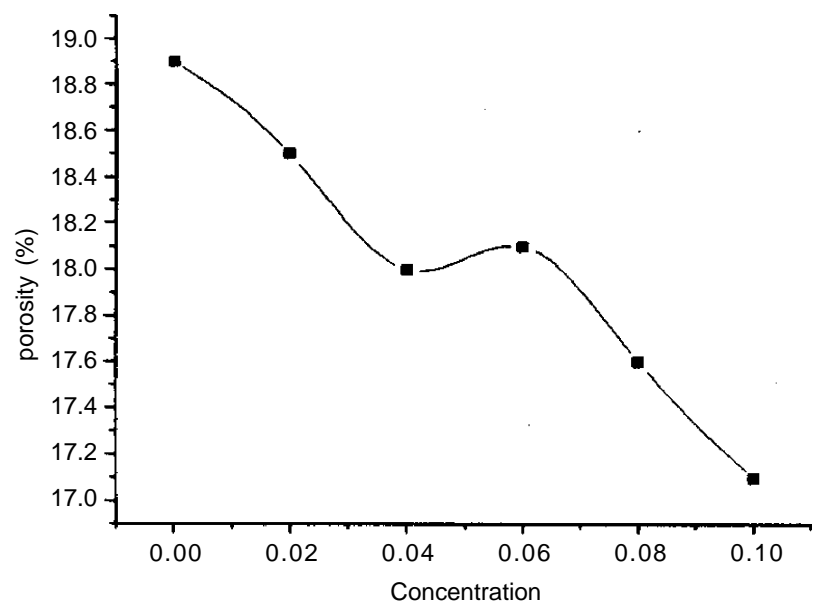

Figure 2. Variation of porosity with Co concentration for $\mathrm{Li}_{0.4-0.5 \mathrm{x}} \mathrm{Zn}_{0.2} \mathrm{Co}_{\mathrm{x}} \mathrm{Fe}_{2.4-0.5 \mathrm{x}} \mathrm{O}_{4}, \mathrm{x}=0.00-0.1$ in steps of 0.02 .

Introduction of $\mathrm{Co}^{2+}$ ions in lithium zinc ferrites greatly affects the electrical properties. The compositional variation of dielectric constant and d.c. resistivity shows inverse trends of variation with each other supporting that dielectric constant is inversely proportional to d.c resistivity [7]. The dielectric constant is found to decrease with increase in Co content. It can be explained on the basis of space charge polarization and Koop's two layer model, where the ferrite is assumed to be made up of well conducting grains separated by poor conducting layers or grain boundaries [8]. The variation of dielectric constant with Co content may be explained by space charge polarization which is formed due to a

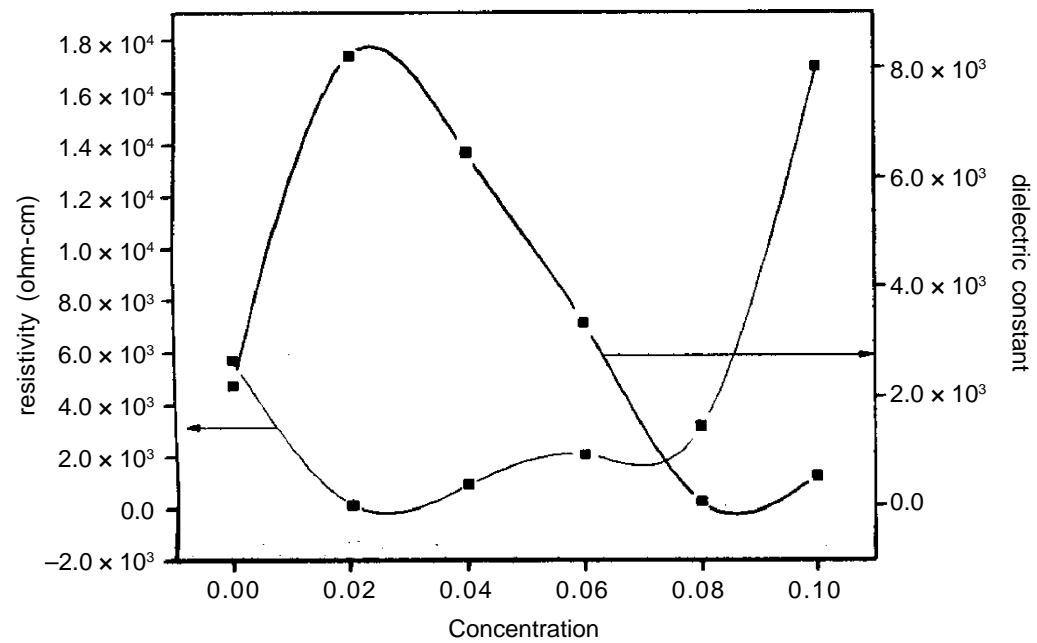

Figure 3. Variation of room temperature resistivity and room temperature dielectric constant as a function of concentration for $\mathrm{Li}_{0.4-0.5 \mathrm{x}} \mathrm{Zn}_{0.2} \mathrm{Co}_{\mathrm{x}} \mathrm{Fe}_{2.4-0.5 \mathrm{x}} \mathrm{O}_{4}, \mathrm{x}=0.00-0.1$ in steps of 0.02 . 
mechanism similar to conduction mechanism. The electrical conduction in ferrite can be explained by Verwey hopping mechanism of electron [9, 10]. Accordingly, electronic conduction in ferrites occurs due to hopping of electron between ions of same element present in more than one valence state, distributed randomly over crystalligraphically equivalent lattice sites, Ferrites structurally form cubic closed packed oxygen lattices with cations at octahedral (B) and tetrahedral (A) sites. B-B hopping is the dominant mode of conduction as distance between two metal ions at $B$ site is smaller than distance between metal ions at $A$ and $B$ sites; and $A-A$ hopping is ignored for reason that $\mathrm{Fe}^{2+}$ ions formed during material synthesizing occupy only the $B$ sites. Thus in the lithium zinc cobalt ferrite with cationic formula [11]

$$
\left(\mathrm{Zn}_{0.2} \mathrm{Fe}_{0.8}\right)\left[\mathrm{Li}_{0.4-0.5 \mathrm{x}} \mathrm{Co}_{\mathrm{x}} \mathrm{Fe}_{1.6-0.5 \mathrm{x}}\right] \mathrm{O}_{4} \text {. }
$$

the $\mathrm{Co}^{2+}$ ions occupies the octahedral $\mathrm{B}$ site, hence conduction may be taken to be the electronic hopping between $\mathrm{Fe}^{3+}$ ions and $\mathrm{Fe}^{2+}$ ions at $\mathrm{B}$ sites. As Co content is increased there is a decrease in the $\mathrm{Fe}^{3+}$ ions at $\mathrm{B}$ sites. The no. of $\mathrm{Fe}^{2+}$ ions formed also decreases as this depends on the content of $\mathrm{Fe}^{3+}$ ions. This reduces the hopping electrons, $\mathrm{Fe}^{2+}$ $\rightleftharpoons \mathrm{Fe}^{3+}$. As a result the piling up of electrons at grain boundary is decreased, impeding the build up of space charge polarization. The value of dielectric constant therefore decreases, as shown in Figure 3. with increasing $\mathrm{Co}^{2+}$ content.

The decrease in the $\mathrm{Fe}^{3+}$, content at $\mathrm{B}$ site with substitution, leads to lesser formation of $\mathrm{Fe}^{2+}$ at $\mathrm{B}$ site. This reduces the $\mathrm{B}-\mathrm{B}$ hopping between $\mathrm{Fe}^{3+}$ and $\mathrm{Fe}^{2+}$ ions, resulting in an increase of resistivity. The observed variation can therefore be understood. The initial decrease in resistivity may be due to the addition of $\mathrm{Co}^{2+}$ ions which may be converted to $\mathrm{Co}^{3+}$ and vice versa. Thus there may be some contribution to conduction to electron exchange $\mathrm{Co}^{2+} \rightleftharpoons \mathrm{Co}^{3+}$ leading to a decrease of resistivity.

\section{Conclusion}

A series of Co substituted lithium zinc ferrites were successfully prepared by sol gel auto combustion process. The substituion of $\mathrm{Co}^{2+}$ greatly affects certain properties of lithium zinc ferrites. The lattice parameter increases. The samples are densified as is indicated by the decrease in porosity. The dielectric constant decreases. However the divalent $\mathrm{Co}^{2+}$ ion substitution enhances the dc resistivity of the basic lithium zinc ferrites.

\section{Acknowledgment}

The author (Ibetombi Soibam) would like to thank DRDO New Delhi for financial support.

\section{References}

[1] B K Kuanr, P K Singh, P Kishan, N Kumar, S L N Rao, P K Singh and G P Srivastava J. Appl. Phys. 863 (1986)

[2] H B Im and D G Wickham IEEE Transaction on magnetics 8765 (1972)

[3] Z Yue, Ji Zhou, X Wang, Z Gui and L Li J. European Ceramic Society 23189 (2003) 
[4] I Soibam, S Phanjoubam and H N K Sarma AIP Conf. Proc. 1003 p.136 (2008)

[5] M Maisnam, S Phanjoubam, H N K Sarma, C Prakash, L Radhapiyari Devi and O P Thakur Physica B370 1 (2005)

[6] K S Mohan and Y C Venudhar J. Material Science Letters 18299 (1999)

[7] J Smit and H P J Wijn Ferrites Philips Technical Library Einthoven Netherland Ch 12 p 240 (1959)

[8] C G Koops Phys. Rev. 83121 (1951)

[9] E J W Verwey and J H de Boer Recl. Trav. Chim. Pays Bass 55331 (1936)

[10] E J W Verwey, P W Haayman and F C Romeijn J. Chem. Phys. 15181 (1947)

[11] P Beuzelin, P Feldmann and W Simonet IEEE Transaction on Magnetics 173135 (1981) 